\title{
Polytrauma patients in the Netherlands and the USA: A bi-institutional comparison of
}

processes and outcomes of care.

Short title: International comparison of polytrauma outcomes

Key words: trauma systems, poly trauma, hospital mortality, trauma outcomes, Injury

Severity Score, The Netherlands, The United States of America.

$\underline{\text { Suzan Dijkink }}{ }^{1}$ MD, Gwendolyn M. van der Wilden ${ }^{1}$ MD PhD, Pieta Krijnen ${ }^{1} \mathrm{PhD}$, Lisa Dol ${ }^{1}$ MD, Steven Rhemrev ${ }^{2}$ MD PhD, David R. King ${ }^{3}$ MD, Marc A. de Moya ${ }^{3}$ MD, George C.

Velmahos ${ }^{3} \mathrm{MD} \mathrm{PhD}$, Inger B. Schipper ${ }^{1} \mathrm{MD} \mathrm{PhD}$

${ }^{1}$ Department of Surgery, Leiden University Medical Center

2 Department of Surgery, Haaglanden Medical Center

${ }^{3}$ Division of Trauma, Emergency Surgery, and Surgical Critical Care, Department of

Surgery, Massachusetts General Hospital

\section{Corresponding author}

Suzan Dijkink MD

Department of Surgery, post zone K6-R

P.O. Box 9600

2300 RC Leiden, the Netherlands

Fax number: +3171 5266750

Phone number: +3171 5261065

S.Dijkink@lumc.nl 


\begin{abstract}
Background: Modern trauma systems differ worldwide, possibly leading to disparities in outcomes. We aim to compare characteristics and outcomes of blunt polytrauma patients admitted to two Level 1 Trauma Centers in the US (USTC) and the Netherlands (NTC).
\end{abstract}

Methods: For this retrospective study the records of 1,367 adult blunt trauma patients with an Injury Severity Score (ISS) $\geq 16$ admitted between July 1, 2011 and December 31, 2013 (640 from NTC, 727 from USTC) were analysed.

Results: The USTC group had a higher mean Charlson Comorbidity Index (median [interquartile range, IQR] 0 [0-2] vs. 0 [0-4], p<0.0001) and Injury Severity Score (median 25 [IQR 17-29] vs. 21[IQR 17-26], p<0.0001). The in-hospital mortality was similar in both centers (11\% in USTC vs. 10\% NTC), also after correction for baseline differences in patient population in a multivariable analysis (OR $0.95,95 \% \mathrm{CI} 0.61-1.48, \mathrm{p}=0.83)$. USTC patients had a longer Intensive Care Unit stay (median 4 [IQR 2-11] vs. 2 [IQR 2-7] days, p=0.006) but had a shorter hospital stay (median 6 [IQR 3- 13] vs. 8 [IQR 4-16] days, p<0.0001). USTC patients were discharged more often to a rehabilitation center (47\% vs $10 \%)$ and less often to home ( $46 \%$ vs. $66 \%, \mathrm{p}<0.0001$ ), and had a higher readmission rate $(8 \%$ vs. $4 \%$, $\mathrm{p}=0.01)$.

Conclusion: Although several outcome parameters differ in two urban area trauma centers in the USA and the Netherlands, the quality of care for trauma patients, measured as survival, is equal. Other outcomes varied between both trauma centers, suggesting that differences in local policies and processes do influence the care system, but not so much the quality of care as reflected by survival. 


\section{Introduction}

Despite several internationally accepted standards for trauma care, there is still significant variation among countries according to unique national demands and regulations. In the United States of America (U.S.), trauma care is organized according to the recommendations set by the American College of Surgeons Committee on Trauma (ACS-COT).(1) With five levels for Trauma Center designation and strict criteria for the resources required at each level, trauma care in the U.S. has been regionalized and the outcomes have improved after the implementation of the trauma system.(2-4)

The Dutch trauma system is comparable to the U.S. model in many ways. In 1999, the Dutch government designated 10 hospitals as trauma centers in an effort to regionalize prehospital patient triage of severely injured patients. (5) All hospitals were categorized into level 1,2 , or 3 trauma centers, based on nationally adopted trauma level criteria set by the Dutch Society for Trauma Surgery and closely resembling the ACS-COT criteria. Currently, the Dutch system is organized in eleven trauma regions, with a coordinating level 1 trauma center commanding a catchment area of minimally 1.2 million inhabitants in every region.(6) In The Netherlands, the implementation of trauma centers has reduced the overall mortality risk by $16 \%$, and by $21 \%$ in polytrauma patients. $(7,8)$

Despite the similarities between the U.S. and the Dutch trauma systems, differences do exist, for instance regarding trauma training, patient volumes, type of injuries, prehospital care, distances travelled, and access to rehabilitation, possibly leading to differences in outcomes of care. The purpose of this study was to compare two urban Level-1 Trauma 
Centers, one in the U.S. and the other in the Netherlands, regarding demographics, injury characteristics, and outcomes of severely injured patients after blunt trauma. 


\section{Material and Methods}

\section{$\underline{\text { Trauma centers }}$}

This retrospective cohort study was performed at the Level 1 Trauma Center of the Massachusetts General Hospital in Boston, USA (USTC) and two Level 1 locations of Trauma Center West Netherlands (NTC), the Haaglanden Medical Center Westeinde and Leiden University Medical Center. The same trauma protocols apply for both Dutch trauma center locations and a previous study demonstrated that the characteristics of the polytrauma patients were similar. No differences were found in in-hospital mortality adjusted for clinical predictors between both Dutch trauma center locations (unpublished data).

The basic characteristics of trauma organization and management of USTC and NTC are summarized in Table 1. Differences were noted in the catchment area, the number of patients admitted annually, and the composition of the trauma team.

The Institutional Review Boards of both trauma centers granted permission for this study.

\section{$\underline{\text { Patients and data collection }}$}

All trauma patients admitted to the NTC or USTC following a blunt trauma between July 1, 2011 and December 31, 2013, older than 16 years of age, and with an Injury Severity Score (ISS) of 16 or higher, were included for analysis. Patients who died before arrival or in the emergency department were excluded from the analysis. Also, patients who were first managed in another hospital before arriving at the NTC or USTC were excluded. 
Patients were identified in the trauma registries of the two trauma centers. $(9,10)$ Data obtained from the trauma registries were supplemented in identical databases in each TC by information acquired from the electronic medical records.

$\underline{\text { Data }}$

Demographic data, type and severity of injuries classified according to the Abbreviated Injury Scale (AIS update 1998) (11), Injury Severity Score (ISS) (12), and vital signs and Revised Trauma Score (RTS) on admission were obtained from the trauma registries.(13) Missing data for the RTS were determined based on vital signs documented in the hospital records in $16.3 \%$ of all the cases in both trauma centers. Injuries with AIS code $>2$ were considered serious injuries. Data on comorbidity, intubation, and complications was collected from the medical charts. To describe the pre-trauma condition of the patients, the Charlson Comorbidity Index (CCI) was calculated by using a Microsoft Excel Macro.(14, 15) The APACHE II score was used to assess the severity of illness of the patients admitted to the Intensive Care Unit (ICU).(16)

The primary outcome was in-hospital mortality. Secondary outcomes included length of stay in the hospital (HOS-LOS) and the ICU (ICU-LOS), ventilator-free days, complications (surgical complications including superficial and deep surgical site infections and rebleeding, pneumonia, urinary tract infections (UTI), deep venous thrombosis (DVT) and pulmonary embolism), readmission, and discharge disposition. 


\section{$\underline{\text { Statistical analysis }}$}

After data collection, the two TC databases were merged for statistical analysis. The demographic and clinical characteristics of the (NTC and USTC populations were compared by univariable analysis. Normally distributed continuous variables were summarized as mean \pm standard deviation (SD) and compared using unpaired t-tests. Skewed continuous data were summarized as median and interquartile range (IQR), and compared using Wilcoxon rank sum tests. Categorical variables were summarized as number (\%), and compared using the Chi-squared test. The odds ratio's with 95\% confidence interval (CI) for in-hospital mortality, ICU-admission, complications and (unplanned) readmission after polytrauma in the NTC compared to the USTC were calculated using multivariable logistic regression analysis. Multiple linear regression analysis was used to calculate the mean difference (with $95 \% \mathrm{CI}$ ) in HOS-LOS and ICU-LOS between the NTC and USTC. In all multivariable analyses, available relevant clinical characteristics (age, gender, CCI, ISS and RTS) were included as independent variables to adjust for differences in case mix between the USTC and NTC. In the multivariable analysis for unplanned readmission, discharge disposition was also added as an independent variable. In the multiple linear regression analysis used to analyze ICU-LOS the APACHE-score was also added. For this observational study, no hypothesis was prespecified, and therefore no formal sample size was calculated.

Two-sided p-values $<0.05$ were considered statistically significant . The statistical analyses were performed using IBM SPSS Statistics for Windows, version 23 (IBM Corp., Armonk, N.Y., USA). 


\section{Results}

\section{Comparison of trauma populations}

Over the study period, 853 blunt polytrauma patients in the NTC and 1520 patients in the USTC met the inclusion criteria. Application of the exclusion criteria resulted in 640 NTC patients and 727 USTC patients eligible for analysis (Figure1).

Table 2 presents the characteristics of the patients in both trauma centers. USTC patients were more frequently male and had higher CCI and ISS compared to NTC patients. Figure 2 shows that USTC patients had more often serious injuries in the chest (43.6\% vs. $37.8 \%, \mathrm{p}=0.02)$ and extremities $(29.6 \%$ vs. $19.5 \%, \mathrm{p}<0.0001)$, as well as injuries in more than one body region $(47.5 \%$ vs. $34.7 \%, \mathrm{p}<0.0001)$.

\section{In-hospital mortality}

The crude in-hospital mortality rate was $10.0 \%$ at the NTC and $10.9 \%$ at the USTC $(\mathrm{p}=0.60)$ (Table 3) with an unadjusted odds ratio for mortality at the NTC compared to the USTC of 0.91 (95\% CI 0.64-1.29). After correction for differences in patient populations at baseline, the adjusted odds ratio for in-hospital mortality in the NTC compared to the USTC was 0.95 (95\% CI 0.61-1.48; p=0.83) (Table 4). Higher age, ISS, and RTS $<12$ were statistically significant predictors of in-hospital mortality in the model.

\section{$\underline{\text { Secondary outcome measures }}$}

HOS-LOS was longer for NTC patients compared to USTC patients (Table 3). Admission rates for the ICU were similar for both trauma centers but, when admitted, ICULOS was longer at the USTC. (Table 3) These results were unchanged after correction for 
differences in clinically relevant variables between the patient populations in the multivariable analyses (data not shown). In ICU-admitted patients, the number of ventilatorfree days was also comparable between the two hospitals (Table 3).

DVT occurred more frequently in the USTC patients compared to the NTC patients ( $2.2 \%$ vs. $0.3 \%, p=0.002)$. The incidence of other complications was comparable between the centers.

There was a statistically significant difference in discharge destination between the trauma centers $(\mathrm{p}<0.0001)$; more NTC patients were sent home compared to USTC patients (66.3\% vs. $46.1 \%)$, whereas more USTC patients were sent to a rehabilitation center $(46.8 \%$ vs. 9.7\%). The unadjusted unplanned readmission rate after the primary admission was higher in the USTC (7.6\% vs. $4.2 \%, \mathrm{p}=0.01)$ (Table 3$)$. This association was no longer statistically significant after correction for clinically relevant differences in the case mix of the patient populations (odds ratio $0.63,95 \%$ CI $0.35-1.15, \mathrm{p}=0.13$ ). Discharge to any other location than home was predictive for readmission in the multivariable model (data not shown). 


\section{Discussion}

In an overseas collaboration between two trauma centers in the Netherlands and the United States we compared the demographic and outcome characteristics of polytrauma patients. Despite relevant differences in case mix, morbidity, complication rates, ICU and hospital length of stay the in-hospital mortality and 30- day mortality were comparable between the centers. A difference in discharge disposition existed with the majority of USTC patients being discharged to a rehabilitation center and the majority of NTC patients being discharged home.

In-hospital mortality was $10 \%$ in both trauma centers, which is similar to or lower than the percentage found in other studies. $(2,7,8,17-20)$ Nearly every other outcome examined differed between both centers. For example, hospital stay was longer at the NTC but ICU stay longer at the USTC. The prolonged ICU stay at the USTC is most likely related to unavailability of floor beds. The USTC operates constantly at a 100\% capacity, which may result in delays in ICU discharge when a floor bed is not empty. Another possible explanation is the use of a Medium Care Unit (MC-unit) in TCWN in which patients can be closely monitored but cannot receive advanced respiratory support. This unit makes it possible to transfer patients out of the ICU if they are weaned from the ventilator even if they still need close monitoring. Despite the differences in ICU-LOS, these numbers are in agreement with those found in other North American and Dutch studies. $(17,21)$

The average total hospital length of stay of NTC patients was statistically and clinically significantly longer compared to USTC patients, but comparable or even shorter than that reported in other studies from the Netherlands. $(7,17)$ The shorter length of stay for USTC patients might be explained by the fact that more patients were discharged to 
rehabilitation centers, suggesting a difference in discharge disposition policy. There are indeed differences between both countries in the organization of care after discharge from the hospital. In the Netherlands home support after discharge is very common and well organized. Most hospitals have a specialized nurse who is responsible for discharge disposition. Based on the advice of the doctor, nurses, and often a physical therapist, the best discharged location is determined. If home is the decided discharge location, home support will be organized. Home support is given by well-trained community health nurses who help patients with their personal care but are also able to provide more advanced medical care such as wound care. The USTC in this study has a close collaboration with an extensive regional rehabilitation network, a consortium of advanced rehabilitation centers. In these institutes patients not only receive intensive rehabilitative therapy but also medical care, thus allowing for earlier discharge from the hospital. It has been suggested that the establishment of trauma centers influenced discharge policies with an increasing number of patients being discharged to a rehabilitation center in the US. (22) A study by Brotemarkle et al. in the elderly trauma population showed that many factors, beside demographic and clinical characteristics, such a personal circumstances (e.g., family support, type of housing), financial (e.g. insurance) and political factors( e.g., organization health care), play a role in the discharge disposition.(23) In this study, data on these types of personal, financial and political factors were not available and could not be compared.

Although the readmission rates in both centers fell within the range of rates reported in literature (4.3-14.6\%) (24-26), these rates differed between the centers. The higher readmission rate in the USTC might be influenced by the varying discharge dispositions between the centers. A study by Copertino et al. identified discharge disposition to a 
rehabilitation center or nursing facility as predictors for readmission. Also in our study, discharge to any other location than home was as well identified as a statistically significant predictor for readmission. Other established predictors for readmission in the literature, comorbidities (CCI) and ISS, were not found to be statistically significant predictors in our study.(27)

Last to be mentioned are the higher deep venous thrombosis rates seen in USTC. DVT is a common complication in admitted trauma patients, with rates ranging from 5-58\% in the literature depending on the populations and diagnostic methods used. (28) Risk factors for the development of a DVT are longer ICU stay, $\geq 3$ ventilator days, age $\geq 40$, venous injury and lower extremity fracture with AIS $\geq 3$. $(29,30)$ Our study showed that USTC patients had more risk factors, such as longer ICU stay and more lower extremity injuries, which might the explain the higher incidence of DVT in the USTC.

$\underline{\text { Strengths and limitations }}$

A strength of our study is the detailed collection of data in comparison to previous publications on this topic. Data from the trauma registry was complemented by data collected from electronic medical records. Although our study is limited by its retrospective design the amount of missing data was minimal and all data was collected in a uniform manner by one researcher $(\mathrm{SD})$. This was in contrast to other studies that used trauma registries established in two different countries without collecting more detailed data.(31) We excluded patients who were managed in another hospital before being admitted to one of the participating centers. Although the literature shows that there is no difference in mortality between transferred and non-transferred patients, it has been shown that there are differences in complications and time between injury and definitive care. $(32,33)$ Exclusion of transferred 
patients from our analyses may have caused a biased interpretation of the patient population at the USTC, because about $50 \%$ of the polytrauma patient population was managed at another (typically small) hospital first. Since it was not feasible to collect the primary data of these transferred patients, we felt compelled to exclude them from our study group. Lastly, although we feel that the NTC and USTC are representative for Level 1 trauma centers in the US and the Netherlands, they may not offer an complete representation of the trauma systems in these two countries.

\section{Conclusion}

The in-hospital mortality for polytrauma patients of two Level 1 trauma centers in two Western countries was similar, but there were notable differences in several other outcomes. Possible differences in critical care delivery, discharge disposition policies, and availability of rehabilitation centers may have contributed to these differences. As we move to integrated and standardized systems of trauma care around the world, it may be important to continue comparing trauma systems worldwide in order to uncover differences in outcomes. Such differences may point to best practices, which when applied, could improve care worldwide. 


\section{Author Contribution}

S.Dijkink contributed to the literature search. S.Dijkink, G.M. Van Der Wilden, P. Krijnen, L.Dol, S.Rhemrev, D.R.King, M.A DeMoya, G.C. Velmahos and I.B. Schipper contributed to the conception and design of the research. S.Dijkink and L.Dol contributed to the data collection. S.Dijkink, L.Dol and P.Krijnen contributed to the data analysis. S.Dijkink, G.M. Van Der Wilden, P.Krijnen, G.C. Velmahos, I.B. Schipper contributed to the data interpretation. S.Dijkink drafted the manuscript. All authors critically revised the manuscript, read and approved the final manuscript, and agree to be fully accountable for ensuring the integrity and accuracy of the work. 


\section{References}

1. American College of Surgeons - Committee on Trauma . Resources for optimal care of the injured patients. American College of Surgeons,; Chicago, 1999.

2. MacKenzie EJ, Rivara FP, Jurkovich GJ, Nathens AB, Frey KP, Egleston BL, et al. A national evaluation of the effect of trauma-center care on mortality. The New England journal of medicine. 2006;354(4):366-78.

3. Nathens AB, Brunet FP, Maier RV. Development of trauma systems and effect on outcomes after injury. Lancet. 2004;363(9423):1794-801.

4. Celso B, Tepas J, Langland-Orban B, Pracht E, Papa L, Lottenberg L, et al. A systematic review and meta-analysis comparing outcome of severely injured patients treated in trauma centers following the establishment of trauma systems. The Journal of trauma. 2006;60(2):371-8; discussion 8 .

5. ten Duis HJ, van der Werken C. Trauma care systems in The Netherlands. Injury. 2003;34(9):722-7.

6. Ministry of Health, Welfare and Sport. Beleidsvisie Traumazorg 2006-2010. Den Haag: Dutch Government; 2006.

7. Spijkers AT, Meylaerts SA, Leenen LP. Mortality decreases by implementing a level I trauma center in a Dutch hospital. The Journal of trauma. 2010;69(5):1138-42.

8. Twijnstra MJ, Moons KG, Simmermacher RK, Leenen LP. Regional trauma system reduces mortality and changes admission rates: a before and after study. Annals of surgery. 2010;251(2):339-43.

9. Sturms LM, Hoogeveen JM, Le Cessie S, Schenck PE, Pahlplatz PV, Hogervorst M, et al. Prehospital triage and survival of major trauma patients in a Dutch regional trauma system: relevance of trauma registry. Langenbeck's archives of surgery / Deutsche Gesellschaft fur Chirurgie. 2006;391(4):343-9.

10. Ewing M, Funk GA, Warren AM, Rapier N, Reynolds M, Bennett M, et al. Improving National Trauma Data Bank(R) coding data reliability for traumatic injury using a prospective systems approach. Health Informatics J. 2015.

11. Association for the Advancement of Automatic Medicine. The Abbreviated Injury Scale, 1990 Revision, Update 98. Barrington, USA 2001.

12. Baker SP, O'Neill B, Haddon W, Jr., Long WB. The injury severity score: a method for describing patients with multiple injuries and evaluating emergency care. The Journal of trauma. 1974;14(3):187-96.

13. Champion HR SW, Copes WS, Gann DS, Gennarelli TA, Flanagan ME. A Revision of the Trauma Score. Journal of Trauma and Acute Care Surgery. 1989;29(5):623-9.

14. Charlson ME, Pompei P, Ales KL, MacKenzie CR. A new method of classifying prognostic comorbidity in longitudinal studies: development and validation. J Chronic Dis. 1987;40(5):373-83.

15. Hall WH, Ramachandran R, Narayan S, Jani AB, Vijayakumar S. An electronic application for rapidly calculating Charlson comorbidity score. BMC Cancer. 2004;4:94. 
16. Zimmerman JE, Wagner DP, Draper EA, Wright L, Alzola C, Knaus WA. Evaluation of acute physiology and chronic health evaluation III predictions of hospital mortality in an independent database. Crit Care Med. 1998;26(8):1317-26.

17. Gunning AC, Lansink KW, van Wessem KJ, Balogh ZJ, Rivara FP, Maier RV, et al. Demographic Patterns and Outcomes of Patients in Level I Trauma Centers in Three International Trauma Systems. World J Surg. 2015;39(11):2677-84.

18. Lansink KW, Gunning AC, Spijkers AT, Leenen LP. Evaluation of trauma care in a mature level I trauma center in the Netherlands: outcomes in a Dutch mature level I trauma center. World J Surg. 2013;37(10):2353-9.

19. Nathens AB, Jurkovich GJ, Maier RV, Grossman DC, MacKenzie EJ, Moore M, et al. Relationship between trauma center volume and outcomes. JAMA. 2001;285(9):1164-71.

20. Templeton J, Oakley PA, MacKenzie G, Cook AL, Brand D, Mullins RJ, et al. A comparison of patient characteristics and survival in two trauma centres located in different countries. Injury. 2000;31(7):493-501.

21. Brinkman S, Bakhshi-Raiez F, Abu-Hanna A, de Jonge E, de Keizer NF.

Determinants of mortality after hospital discharge in ICU patients: literature review and Dutch cohort study. Crit Care Med. 2013;41(5):1237-51.

22. Kelly ML, Roach MJ, Banerjee A, Steinmetz MP, Claridge JA. Functional and longterm outcomes in severe traumatic brain injury following regionalization of a trauma system. J Trauma Acute Care Surg. 2015;79(3):372-7.

23. Brotemarkle RA, Resnick B, Michaels K, Morton P, Wells C. Length of hospital stay and discharge disposition in older trauma patients. Geriatr Nurs. 2015;36(2 Suppl):S3-9.

24. Moore L, Stelfox HT, Turgeon AF, Nathens AB, Le Sage N, Emond M, et al. Rates, patterns, and determinants of unplanned readmission after traumatic injury: a multicenter cohort study. Annals of surgery. 2014;259(2):374-80.

25. Morris DS, Rohrbach J, Sundaram LM, Sonnad S, Sarani B, Pascual J, et al. Early hospital readmission in the trauma population: are the risk factors different? Injury. 2014;45(1):56-60.

26. Laupland KB, Svenson LW, Grant V, Ball CG, Mercado M, Kirkpatrick AW. Longterm mortality outcome of victims of major trauma. Injury. 2010;41(1):69-72.

27. Copertino LM, McCormack JE, Rutigliano DN, Huang EC, Shapiro MJ, Vosswinkel JA, et al. Early unplanned hospital readmission after acute traumatic injury: the experience at a state-designated level-I trauma center. Am J Surg. 2015;209(2):268-73.

28. Rogers FB, Cipolle MD, Velmahos G, Rozycki G, Luchette FA. Practice management guidelines for the prevention of venous thromboembolism in trauma patients: the EAST practice management guidelines work group. The Journal of trauma. 2002;53(1):142-64. 29. Michetti CP, Franco E, Coleman J, Bradford A, Trickey AW. Deep vein thrombosis screening and risk factors in a high-risk trauma population. J Surg Res. 2015.

30. Knudson MM, Ikossi DG, Khaw L, Morabito D, Speetzen LS. Thromboembolism after trauma: an analysis of 1602 episodes from the American College of Surgeons National Trauma Data Bank. Annals of surgery. 2004;240(3):490-6; discussion 6-8.

31. Jurkovich GJ, Mock C. Systematic review of trauma system effectiveness based on registry comparisons. The Journal of trauma. 1999;47(3 Suppl):S46-55.

32. Pickering A, Cooper K, Harnan S, Sutton A, Mason S, Nicholl J. Impact of prehospital transfer strategies in major trauma and head injury: systematic review, meta- 
analysis, and recommendations for study design. J Trauma Acute Care Surg. 2015;78(1):16477.

33. Hill AD, Fowler RA, Nathens AB. Impact of interhospital transfer on outcomes for trauma patients: a systematic review. The Journal of trauma. 2011;71(6):1885-900;

discussion 901. 
Figure 1 Flowchart of patient selection

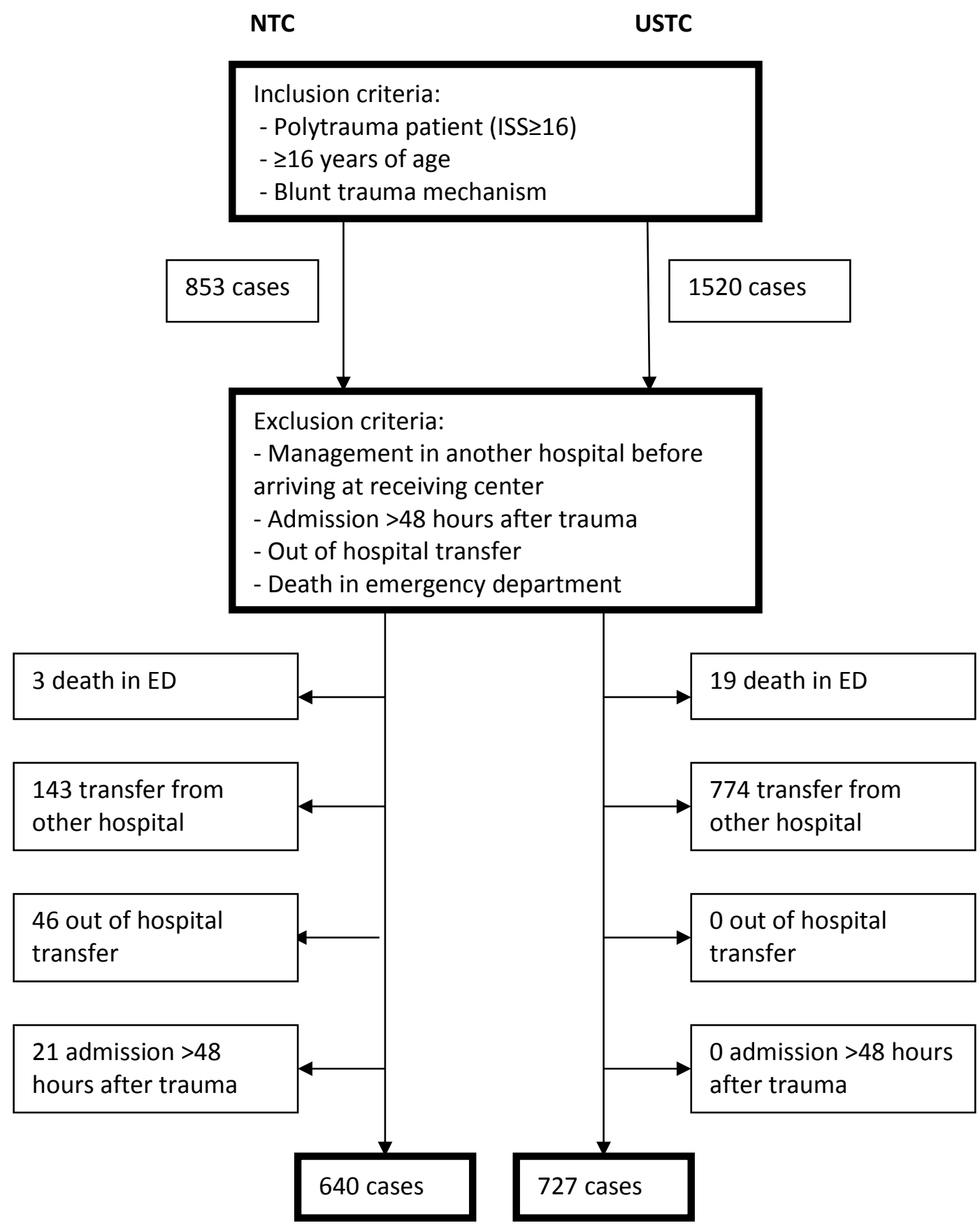


Figure 2 Distribution of injured body regions (AIS $>2$ ) by trauma center

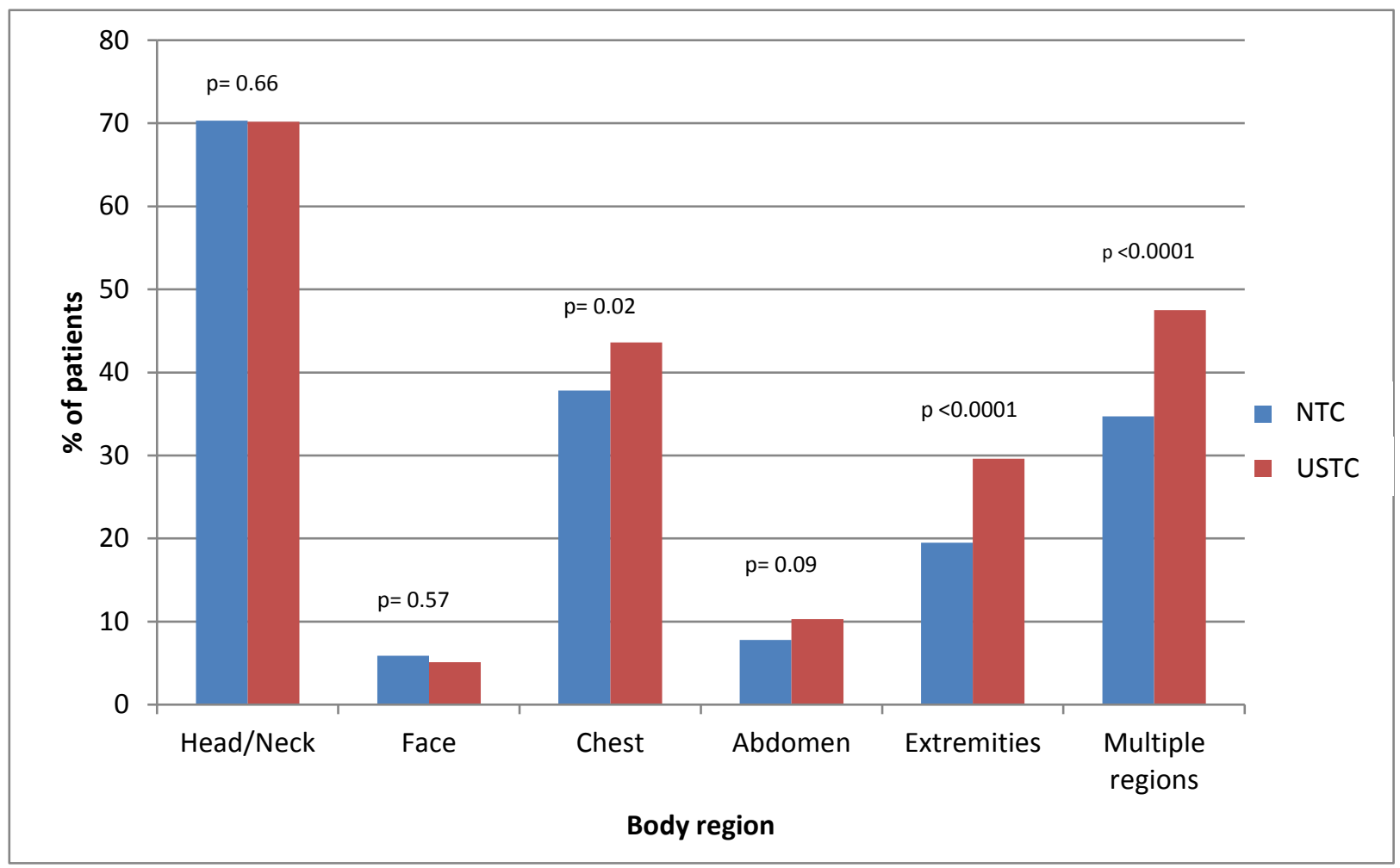

AIS: Abbreviated Injury Score; NTC: Trauma Center West Netherlands; USTC: Massachusetts General Hospital 
Table 1. Characteristics of trauma systems

\begin{tabular}{|c|c|c|}
\hline & NTC & USTC \\
\hline Level trauma center & 1 & 1 \\
\hline Number of locations & 2 & 1 \\
\hline Hospital catchment area & $\begin{array}{l}\text { Urban area } \\
2.0 \text { million } \\
\text { inhabitants }\end{array}$ & $\begin{array}{l}\text { Urban area } \\
6.0 \text { million } \\
\text { inhabitants }\end{array}$ \\
\hline $\begin{array}{l}\text { Total number of trauma patients/ } \\
\text { year }\end{array}$ & 2270 & 2500 \\
\hline Polytrauma patients/year & 400 & 600 \\
\hline ATLS training & Yes & Yes \\
\hline $\begin{array}{l}\text { Protocol 'Management of } \\
\text { polytrauma patients' available }\end{array}$ & Yes & No \\
\hline $\begin{array}{l}\text { Specific criteria for activation of the } \\
\text { trauma team }\end{array}$ & Yes & Yes \\
\hline $24 / 7$ in house coverage & $\begin{array}{l}\text { Yes (junior surgical } \\
\text { resident, under close } \\
\text { supervision of an } \\
\text { attending surgeon) }\end{array}$ & $\begin{array}{l}\text { Yes (attending } \\
\text { surgeon) }\end{array}$ \\
\hline CT-scan available at ED & in 1 of 2 locations & Yes \\
\hline X-ray/ultrasound available at ED & Yes & Yes \\
\hline Operating room available $24 / 7$ & Yes & Yes \\
\hline OR-team available $24 / 7$ & Yes, on call & Yes \\
\hline ICU bed available & Yes & Yes \\
\hline Trauma team members & $\begin{array}{l}\text { Attending surgeon, } \\
\text { surgical resident, } \\
\text { emergency physician, } \\
\text { an anesthesiologist, } \\
\text { intensive care doctor, } \\
\text { radiologist, ICU- } \\
\text { nurse, two emergency } \\
\text { department nurses } \\
\text { and an OR-nurse. }\end{array}$ & $\begin{array}{l}\text { Attending surgeon, } \\
\text { fellow in trauma } \\
\text { surgery (junior } \\
\text { attending), senior } \\
\text { resident, intern, ED } \\
\text { senior resident, ED } \\
\text { junior resident, nurse } \\
\text { practitioner }\end{array}$ \\
\hline $\begin{array}{l}\text { Other specialties available for } \\
\text { consultation }\end{array}$ & Yes & Yes \\
\hline
\end{tabular}


Table 2. Patient characteristics

\begin{tabular}{|c|c|c|c|}
\hline & $\begin{array}{l}\text { NTC } \\
(\mathrm{N}=640)\end{array}$ & $\begin{array}{l}\text { USTC } \\
(\mathrm{N}=727)\end{array}$ & $\mathbf{P}$ \\
\hline Age, mean (SD) & $56.5(21.0)$ & $55.0(23.0)$ & 0.19 \\
\hline Male, n (\%) & $398(62.2)$ & $493(67.8)$ & 0.03 \\
\hline CCI, median (IQR) & $0(0-2)$ & $0(0-4)$ & $<0.0001$ \\
\hline $\begin{array}{l}\text { Trauma mechanism, } \mathrm{n}(\%) \\
\text { Road traffic accident } \\
\text { Fall from height } \\
\text { Assault } \\
\text { Other }\end{array}$ & $\begin{array}{l}242(38.4) \\
353(55.9) \\
16(2.5) \\
20(3.2)\end{array}$ & $\begin{array}{l}280(38.5) \\
375(51.6) \\
34(4.7) \\
38(5.2)\end{array}$ & 0.03 \\
\hline ISS, median (IQR) & $21(17-26)$ & $25(17-29)$ & $<0.0001$ \\
\hline $\begin{array}{l}\text { RTS, n }(\%) \\
\text { RTS } 12 \\
\text { RTS } 11 \\
\text { RTS } \leq 10\end{array}$ & $\begin{array}{l}447(69.8) \\
71(11.1) \\
122(19.1)\end{array}$ & $\begin{array}{l}522(72.4) \\
57(7.9) \\
142(19.7)\end{array}$ & 0.13 \\
\hline $\begin{array}{l}\text { Initial vital signs at ED } \\
\text { SBP, mean (SD) } \\
\text { HR, mean (SD) } \\
\text { GCS, n (\%) } \\
\text { Mild TBI; GCS 13-15 } \\
\text { Moderate TBI; GCS 9-12 } \\
\text { Severe TBI; GCS 3-8 }\end{array}$ & $\begin{array}{l}145.0(30.9) \\
85.0(20.7) \\
464(73.2) \\
60(9.5) \\
110(17.4) \\
\end{array}$ & $\begin{array}{l}143.7(32.6) \\
89.1(22.6) \\
542(75.0) \\
45(6.2) \\
136(18.8) \\
\end{array}$ & $\begin{array}{l}0.46 \\
0.001 \\
0.08\end{array}$ \\
\hline APACHE-score ${ }^{\mathrm{I}}$, median (IQR) & $14(9-24)$ & $20(15-25)$ & $<0.0001$ \\
\hline
\end{tabular}

NTC: Trauma Center West Netherlands; USTC: Massachusetts General Hospital; SD: standard deviation; CCI: Charlson Comorbidity Index; ISS: Injury Severity Score; IQR: interquartile range; RTS: Revised Trauma Score; SBP: systolic blood pressure in mmHg; HR: heart rate in beats/min; GCS: Glasgow Coma Scale; APACHE: Acute Physiology and Chronic Health Evaluation.

${ }^{\mathrm{I}}$ In patients admitted to the Intensive Care Unit ( $\mathrm{n}=303$ in NTC and $\mathrm{n}=373$ in USTC). 
Table 3. Outcomes

\begin{tabular}{|c|c|c|c|}
\hline & $\begin{array}{l}\text { NTC } \\
(N=640)\end{array}$ & $\begin{array}{l}\text { USTC } \\
(\mathrm{N}=727)\end{array}$ & $\mathbf{P}$ \\
\hline In-hospital mortality, n (\%) & $64(10.0)$ & $79(10.9)$ & 0.60 \\
\hline HOS-LOS in days, median (IQR) & $8(4-16)$ & $6(3-13)$ & $<0.0001$ \\
\hline ICU admission, $\mathrm{n}(\%)$ & $303(47.3)$ & $373(51.7)$ & 0.11 \\
\hline ICU-LOS in days ${ }^{\mathrm{I}}$, median (IQR) & $2(2-7)$ & $4(2-11)$ & 0.006 \\
\hline Ventilator-free days ${ }^{\mathrm{I}}$, median (IQR) & $26(17-28)$ & $26(14-28)$ & 0.47 \\
\hline $\begin{array}{l}\text { Complications } \\
\text { Surgical complications }{ }^{\mathrm{II}}, \mathrm{n}(\%) \\
\text { Pneumonia, n (\%) } \\
\text { Urinary tract infection, n (\%) } \\
\text { Deep venous thrombosis, n (\%) } \\
\text { Pulmonary embolism, n (\%) }\end{array}$ & $\begin{array}{l}18(2.5) \\
68(10.6) \\
47(7.3) \\
2(0.3) \\
7(1.1)\end{array}$ & $\begin{array}{l}11(1.7) \\
91(12.5) \\
45(6.2) \\
16(2.2) \\
11(1.5)\end{array}$ & $\begin{array}{l}0.34 \\
0.27 \\
0.40 \\
0.002 \\
0.50 \\
\end{array}$ \\
\hline $\begin{array}{l}\text { Discharge location }{ }^{\mathrm{III}}, \mathrm{n}(\%) \\
\text { Home } \\
\text { Rehabilitation center } \\
\text { Nursing facility } \\
\text { Other institution }\end{array}$ & $\begin{array}{l}382(66.3) \\
56(9.7) \\
104(18.1) \\
34(5.9)\end{array}$ & $\begin{array}{l}299(46.1) \\
303(46.8) \\
25(3.9) \\
21(3.2)\end{array}$ & $<0.0001$ \\
\hline Readmission (unplanned) ${ }^{\mathrm{III}}, \mathrm{n}(\%)$ & $24(4.2)$ & $49(7.6)$ & 0.01 \\
\hline
\end{tabular}

NTC: Trauma Center West Netherlands; USTC: Massachusetts General Hospital; HOS-LOS: hospital length of stay in days; IQR: interquartile range; ICU: intensive care unit; ICU-LOS: intensive care unit length of stay in days; SD: standard deviation.

${ }^{\mathrm{I}}$ Of patients admitted to ICU ( $\mathrm{n}=303$ in NTC and $n=373$ in USTC)

II Surgical site infection (superficial or deep), re-bleeding in operated patients ( $n=230$ in NTC and $n=338$ in USTC).

III Of patients surviving hospital admission ( $\mathrm{n}=576$ in NTC and $\mathrm{n}=648$ in USTC) 
Table 4. Multivariable logistic regression analysis of in-hospital mortality by center, adjusted for differences in patient populations at baseline

\begin{tabular}{lr|l|l}
\hline Factor & & OR (95\% CI) & P \\
\hline Center & USTC & 1 & \\
& NTC & $0.95(0.61-1.48)$ & 0.83 \\
\hline Age & & $1.05(1.03-1.06)$ & $<0.0001$ \\
\hline Gender & & \\
& Female & 1 & 0.58 \\
\hline CCI & Male & $1.14(0.72-1.81)$ & 0.31 \\
\hline ISS & $1.05(0.96-1.14)$ & 0.001 \\
\hline RTS & & $1.04(1.02-1.06)$ & \\
& RTS 12 & 1 & \\
& RTS 11 & $3.44(1.74-6.82)$ & $<0.0001$ \\
& RTS $\leq 10$ & $16.42(9.72-27.73)$ & $<0.0001$ \\
\hline
\end{tabular}

USTC: Massachusetts General Hospital; NTC: Trauma Center West Netherlands; OR: odds ratio; CI: confidence interval; CCI: Charlson Comorbidity Index, ISS: Injury Severity Score, RTS: Revised Trauma Score 